\title{
An Online Colour Naming Workshop
}

\author{
Dimitris Mylonas \\ Laboratory of Neurobiology, UCL \\ dimitris.mylonas@yahoo.com
}

\author{
Lindsay MacDonald \\ Faculty of Media, University of the Arts London \\ L.MacDonald@lcc.arts.ac.uk
}

\section{ABSTRACT}

Extensive research in colour naming has been more focused on a small number of consensual colour categories than towards the development of more subtle colour identifications (Gage 1993, Berlin \& Kay 1969) but how can we communicate "basic" and more "delicate" colour names within and between different cultures in an agreeable way?

This workshop intends to bring attendees up-todate with the findings of a multi-lingual colour naming study conducted over the Internet (Mylonas \& MacDonald 2010, Mylonas et al. 2010). Participants will have the opportunity to play a colour communication card game and win fine art prints illustrated by Valero Doval (Mylonas 2010). Drawing on that experience your cognitive aspects of colour will be compared with the responses of thousands of participants and for the very first time, you will be able to explore an innovative online application (beta), designed to facilitate colour communication over the World Wide Web. Multiple factors that influence colour categorisation will be discussed with visual examples (MacDonald \& Mylonas 2010). This international workshop should be of interest of those associated with colour technology, colour in art and design, experimental psychology, computer vision, linguistics and communication studies.

The online colour naming experiment is currently translated in English, Greek, Spanish, German, Catalan, Italian, Chinese-Mandarin with over 2500 participants (Mylonas \& MacDonald 2008). Please note participation in the colour communication game will proceed on a first-come, first-served basis.

\section{REFERENCES}

Berlin, B. and Kay, P. (1969). Basic color terms: their universality and evolution, Stanford, California.

Gage, J. (1993). Color and culture: practice and meaning from antiquity to abstraction, Thames \& Hudson, London.

MacDonald, L.W. and Mylonas, D. (2010). Edible Color Names, Proc. AIC 2010 Conf. on 'Color and Food', Mar del Plata, Argentina, October 2010, pages 196-199, Grupo Argentino del Color and Nobuko, Argentina.

Mylonas, D. (2010). Colour Naming, Workshop at CREATE,http://tinyurl.com/create-workshops-2010, (10 April 2011).

Mylonas, D. and MacDonald, L.W. (2008). An Online Colour Naming Model, http://colournaming.com, (10 April 2011)

Mylonas, D. and MacDonald, L.W. (2010) Online Colour Naming Experiment Using Munsell Samples, Proc. CGIV 2010, Joensuu, Finland, June 2010, 27-32, IS\&T, Springfield.

Mylonas, D., MacDonald, L.W. and Wuerger S. (2010) Towards an Online Colour Naming Model, Proc. CIC 2010, San Antonio, US, November 2010, pages 140-144, IS\&T, Springfield. 